\title{
Desigualdades da POlítica no Brasil: RePresentação Descritiva NA ELEIÇÃo de 2014 PARA A CÂMARA doS Deputados
}

\author{
Augusto N. C. De Oliveira ${ }^{1}$
}

\begin{abstract}
Resumo
A representação descritiva propõe que o Parlamento deve se formar à imagem da sociedade que o constitui. Por meio dos dados da eleição de 2014 e do Censo 2010, este artigo expõe uma estrutura profundamente desigual na capacidade de acesso ao poder político no Brasil: as mulheres, os negros, os menos escolarizados, os trabalhadores e os pobres estão sub-representados na Câmara dos Deputados. Tanto na oportunidade de concorrer quanto na capacidade de ser eleito, a desigualdade da política no Brasil impõe um enorme desafio à incorporação política da diversidade social no Parlamento. Qual o desafio da democracia brasileira no que concerne à justa representação dos diferentes? No momento em que a noção de uma crise da representação se fortalece, é necessário repensar o que se espera da democracia e como ela pode contribuir para seu designío original, o da igualdade entre os cidadãos.
\end{abstract}

Palavras-chave: Representação descritiva. Desigualdade. Câmara dos deputados. Eleição 2014.

1 Doutor em Ciência Política, Pesquisador da FEE (Fundação de Economia e Estatística Siegfried Emanuel Heuser) e professor da Faculdade de Filosofia e Ciências Humanas da PUCRS, Brasil. augusto.oliveira@fee.tche.br

Este texto beneficiou-se de discussões com Jaques Bensussan, Rober Ávila e Tarson Nuñez, pesquisadores da FEE, bem como das contribuições dos pareceristas anônimos da revista Mediações. Imprecisões remanescentes são de responsabilidade exclusiva do autor. 


\title{
Political inequalities in Brazil: Descriptive Representation in the 2014 elections to the Chamber of Deputies
}

\begin{abstract}
The descriptive representation proposes that Parliament must be formed as the image of the society. Using data of the 2014 federal election and the 2010 Census, this article exposes a deeply unequal structure in the access to political power in Brazil: women, black people, the less educated, workers and the poor are underrepresented in Chamber of Deputies. Both the opportunity to compete as the ability to be elected, the inequality of politics in Brazil poses a huge challenge to the political incorporation of social diversity in Parliament. What is the challenge of Brazilian democracy regarding the fair representation of the different? At the time when the notion of a crisis of representation is strengthened, is necessary rethink what is expected of democracy and how it can contribute to its original design, the equality between citizens.
\end{abstract}

Keywords: Descriptive representation. Inequality. Chamber of deputies. 2014 Election.

\section{INTRODUÇÃO: REPRESENTAÇÃO DESCRITIVA E DEMOCRACIA LIBERAL}

$\mathrm{O}$ presente artigo estuda a desigualdade da representação política na eleição de 2014 para a Câmara dos Deputados brasileira. Com esta intenção, utiliza-se a noção de representação descritiva. Conforme Pitkin (1967), nesta visão o Parlamento é compreendido como miniatura, mapa ou espelho da sociedade: em seu corpo deveria constar a representação dos diferentes grupos sociais que compõem o conjunto da cidadania. A visão da representação descritiva requer que a legislatura seja selecionada de maneira que sua composição corresponda acuradamente à composição de toda a Nação (PITKIN, 1967, p. 60).

Este argumento da representação ganhou saliência na defesa da representação de minorias em sistemas proporcionais, dado o 
risco de que a representação majoritária em uma situação de sufrágio masculino universalizado excluísse do Parlamento os representantes das classes elevadas, os mais escolarizados e ricos. Autores como Mill (1964) supunham que os eleitores escolheriam seus representantes entre seus pares e que eleições majoritárias levariam, inexoravelmente, à exclusão dos mais capazes do Parlamento.

Fórmulas eleitorais proporcionais, portanto, foram pensadas para garantir a presença no Parlamento das minorias sociais. $\mathrm{O}$ debate atual sobre a proporcionalidade das eleições não costuma recorrer às características descritivas dos eleitos e dos eleitores, mas à correspondência entre a manifestação de preferência dos eleitores (seus votos) e a constituição do Parlamento (a divisão das cadeiras). O Parlamento é lido como lugar da representação de opiniões e interesses materializados em partidos políticos e seus programas de governo. Seriam os partidos fiéis depositários da representação da diversidade dos interesses sociais - mais do que da diversidade social propriamente considerada - e por seu intermédio minorias e maiorias apresentam-se no Parlamento.

A representação descritiva pareceria, nesse sentido, uma noção anacrônica e limitada. Pitkin (1967) mostra como na representação orientada por critérios descritivos o representante "está por" seu constituinte de uma maneira formal. Em termos descritivos, a característica ou a semelhança esgota o significado da representação. Nenhuma ação, nenhuma tomada de posição pode ser exigida na defesa dos interesses daqueles que compartilham com o representante seu critério de identidade. Resumida à descrição, a única representação possível é das características salientes dos representados, com exclusão de qualquer conteúdo substantivo e da própria ação política (PITKIN, 1967, p. 63). Nos termos da representação descritiva, a responsabilidade dos parlamentares resume-se a sua presença informativa. 
Dois outros argumentos contrários à redução da representação como descrição podem ser referidos. Um exemplo decorre das propostas conservadoras de representação profissional, presente nos movimentos antiparlamentares do entre guerras na Europa e também no Brasil (BARRETO, 2004). Refletindo sobre seus limites, Kelsen (2000) destaca que as pessoas não possuem apenas um interesse singular, compreendido em um aspecto de suas vidas, razão pela qual a representação profissional seria incompleta. Ademais, as decisões geradas em órgãos formados por representação profissional ficaria adstrita à órbita corporativa de interesses incompatíveis, de maneira que a decisão final sobre as disputas precisaria ser feita por outro órgão, fosse ele baseado na representação individual ou fosse simplesmente não democrático.

A questão da representação profissional exemplifica bem a incompatibilidade entre uma visão da representação como exclusivamente descritiva e a democracia liberal. Um segundo argumento contrário à instituição da representação descritiva é apontado por Arato (2002). O autor repara que o mandato descritivo é incompatível com o pressuposto da liberdade individual do eleitor em escolher seu representante: o eleitor não pode ser forçado a escolher um representante dentre os membros do próprio grupo. Revelase, assim, o caráter autoritário da adstringência dos eleitores a uma das características que os identificam, bem como a arbitrariedade da definição de quais características seriam válidas para formação do Parlamento e quais seriam obliteradas.

As ressalvas da teoria democrática liberal à participação descritiva no Parlamento não obsta, contudo, a percepção de que determinados grupos sociais se fazem representar mais fortemente do que outros. Contrariamente à impressão de seus intérpretes primeiros, a universalização do sufrágio não conduziu a um Parlamento medíocre. Prevaleceu a compreensão clássica segundo a qual entre 
eleições e democracia guarda-se algo de incompatível, tendo em vista que as eleições formam um governo socialmente diferente do povo (ARISTÓTELES, 1997, p. 152). Como atesta a análise de Manin (2012), seja em decorrência desta previsão institucional, seja por força das condições sociais das democracias contemporâneas, as eleições nunca deixaram de constituir um corpo diferenciado dos representantes: uma aristocracia eletiva.

O critério de diferenciação desta aristocracia não recai apenas sobre as características que distinguem favoravelmente os eleitos aos olhos do eleitor, mas também decorrem de regras que distinguem os aptos e os inaptos a concorrer pela preferência dos seus concidadãos. Neste sentido, Santos (1998) destaca o papel das regras que controlam a elegibilidade e o direito de oferecer candidaturas eletivas: limites de idade, requisitos de educação, de domicílio e de filiação partidária são alguns dos critérios que restringem a competição eleitoral muito antes de ela realmente iniciar.

A representação descritiva não participa do conteúdo definidor da democracia liberal. Ela aparece, contudo, enquanto elemento crítico de seus limites, uma abertura que deixa perscrutar e desvelar incongruências ou desigualdades que se materializam em um sentimento de mal-estar com a democracia ${ }^{2}$. Não tem razão o feminismo em denunciar que apenas 10\% desta aristocracia parlamentar seja formada por mulheres? Quem fala em nome desta maioria social no Parlamento? Quem fala em nome dos negros? Quem fala em nome dos pobres?

Young (1989) problematiza a questão da representação dos grupos excluídos em face do princípio democrático liberal do

A constatação de que a ampliação do sufrágio não se fez acompanhar de um governo à imagem do povo permitiu as críticas antiliberais e antiparlamentares de autores como Mosca (1939) na primeira metade do século XX. Diferente da visão da Teoria das Elites, que desconsidera a possibilidade da representação democrática via eleições livres, justas e inclusivas em uma poliarquia (DAHL, 2001), a interpretação da representação descritiva proposta nesta investigação busca revelar um desafio a ser enfrentado no sentido da concretização e aprofundamento da democracia. 
indistinto universalismo da cidadania. Considerando a existência de grupos privilegiados e oprimidos na sociedade, a autora afirma que são indispensáveis o reconhecimento e a efetiva participação dos oprimidos na política - sob pena de o argumento universalista esconder a perpetuação das condições de exercício da opressão de uns sobre os outros. Uma visão próxima da representação descritiva também é revalorizada por Phillips (2001), para quem a efetiva presença na política de membros das minorias sociais ou dos grupos politicamente excluídos, portadores das experiências de vida que compartilham, é essencial para uma representação justa. Pitkin mesmo, em sua investigação seminal, afirma que a representação descritiva obviamente é importante para a vida política - em que pese não esgotar o conteúdo da representação política (PITKIN, 1967, p. 89).

Este artigo desenvolve uma análise concreta do problema da desigualdade da representação descritiva da democracia brasileira, especificamente na eleição da Câmara dos Deputados de 2014. A abordagem é realizada em dois momentos: nas candidaturas lançadas à Câmara dos Deputados ${ }^{3}$ e entre os eleitos. A próxima seção apresenta as considerações metodológicas utilizadas na análise da representação descritiva. Nas seções seguintes são explorados cinco diferentes critérios de representação descritiva: gênero, cor ou raça, grau de instrução (escolarização), ocupação e riqueza. Na conclusão discutemse, a partir dos dados apresentados, algumas questões que poderiam entrar na agenda política, no sentido de aumentar as oportunidades de participação política/institucional dos cidadãos brasileiros, sob um critério de igualdade.

A possibilidade e oportunidade de lançar candidaturas é um limitador da participação ativa relativamente independente do resultado das urnas e dos critérios que, tendencialmente, guiam o comportamento do eleitor. É apenas relativamente independente pois, seja pela atuação das lideranças partidárias, seja pela expectativa da vitória na formação da vontade de participar das eleições como candidato, pode-se esperar que a seleção de candidatos à Câmara dos Deputados reproduza o perfil dos deputados que tradicionalmente alcançam a vitória. 


\section{Considerações metodológicas}

Para investigar a representação descritiva segundo os critérios apresentados, analisou-se a composição das candidaturas à Câmara dos Deputados e o perfil dos deputados eleitos a partir do Repositório de Dados Eleitorais, mantido pelo Tribunal Superior Eleitoral (TSE). Como candidatos foram considerados apenas aqueles que concorreram nas eleições de 2014. Das 7.140 candidaturas inscritas, 965 não participaram do pleito por terem sido indeferidas pela Justiça Eleitoral ou por terem renunciado. Os critérios legais de inelegibilidade relativa e a falta de interesse e/ou capacidade de manter a candidatura podem ser considerados fatores limitadores da participação política anteriores à eleição. Por esta razão, foram consideradas apenas as 6.175 candidaturas que efetivamente participaram do pleito.

A demografia social foi apreendida do Censo 2010 do IBGE. Existe, portanto, uma defasagem de quatro anos entre os dados sociais e a data de realização da eleição. Considerando o caráter estrutural destas informações, não devem ser esperados resultados substancialmente diferentes caso estivessem disponíveis dados censitários para o ano de 2014. Além destas fontes, para o estudo da ocupação dos deputados eleitos foram considerados dados da Câmara de Deputados e para o critério riqueza foram utilizados dados da Receita Federal.

A análise da desigualdade da política nacional em cada um dos cinco critérios elencados recorre a dois instrumentos analíticos. O primeiro é um gráfico que mostra a distribuição da população em geral (círculo externo), das candidaturas à Câmara dos Deputados (círculo intermediário) e do conjunto de deputados eleitos (círculo interno). Esta apresentação permite visualizar a distribuição e a desproporcionalidade da presença dos diferentes grupos no conjunto da sociedade, entre as candidaturas e na Câmara de Deputados eleita. 
O segundo instrumento, apresentado em tabelas, recorre à seguinte formulação. Dado o número de cidadãos () que compartilham determinada característica () e o conjunto da sociedade (); e dado o número de deputados () que compartilham desta mesma característica () eo conjunto da Câmara dos Deputados(), foi calculada a representação descritiva real de cada característica na Câmara dos Deputados e () e a representação descritiva ideal (). Assim, foi possível chegar à proporção da representação ideal conquistada na Câmara dos Deputados pelos cidadãos que compartilham determinada característica ().

Um exemplo (Tabela 1): considere-se uma população de 1.000 pessoas, das quais 700 preferem a cor azul e 300 preferem a cor vermelha.

Tabela 1 - Exemplo do indicador de proporção da representação ideal.

\begin{tabular}{|l|c|c|c|c|c|c|}
\cline { 3 - 7 } \multicolumn{1}{c|}{} & \multirow{2}{*}{ População } & \multicolumn{2}{c|}{ Câmara 1 } & \multicolumn{2}{c|}{ Câmara 2 } \\
\cline { 3 - 7 } & & Absol. & Prop. & Absol. & Prop. \\
\hline Preferem Azul & 700 & 7 & 1,0 & $(100 \%)$ & 3 & $0,4 \quad(40 \%)$ \\
\hline Preferem Vermelho & 300 & 3 & $1,0 \quad(100 \%)$ & 7 & $2,3 \quad(230 \%)$ \\
\hline
\end{tabular}

Fonte: Elaboração própria.

Para um conjunto de 10 indivíduos possuir a representação descritiva ideal da população, sete devem preferir azul e três vermelho (Câmara 1): um representante para cada um que deveria ter $(=1,0)$. Considere-se, agora, um conjunto constituído por três que preferem a azul e sete que preferem vermelho (Câmara 2). Neste caso revelamse duas representações desproporcionais. $\mathrm{O}$ grupo azul possui 0,4 representante para cada representante que deveria ter $(40 \%$, menos do que a metade); o grupo vermelho possui 2,3 representantes para cada representante que deveria ter $(230 \%$, mais do que o dobro). Os dados evidenciam que o grupo azul está sub-representado em face de uma super-representação do grupo vermelho. 


\section{Desigualdade Segundo gênero}

A desigualdade de gênero na política é um fenômeno que recebe atenção da academia tanto no Brasil quanto nas democracias do ocidente. No Brasil, alcançou reconhecimento jurídico com a instituição de cotas pela Lei no 9.504, de 1997. O dispositivo, com redação de 2009, prevê que partidos e coligações obrigatoriamente registrarão nas eleições da Câmara dos Deputados no mínimo 30\% e no máximo 70\% das candidaturas de cada gênero. Como efeito prático as listas das eleições para a Câmara dos Deputados, formuladas na circunscrição estadual, passaram a conter ao menos $30 \%$ de candidatas do gênero feminino. Outro avanço legal diz respeito à fixação de critérios de participação feminina nos recursos obtidos via Fundo Partidário e na Propaganda Eleitoral Gratuita.

Estes dispositivos, entretanto, não são suficientes para lidar com a desigualdade de gênero na política brasileira. Araújo (2005) reflete sobre a interseção entre a representação feminina, a política de cotas e a inserção política por meio dos partidos políticos. A autora aponta que os partidos brasileiros adotam predominantemente uma estratégia de retórica: a questão feminista está presente em seus programas e no debate de ideias, no entanto, na hora de definir as candidaturas, prevalece uma cultura política não igualitária que reproduz a desigualdade presente na sociedade. Mesmo a política de cotas não foi suficiente para balancear um recrutamento eleitoral voltado para perfis eleitorais tradicionais.

A Figura 1 e a Tabela 2 expõe tal constatação no quadro da eleição de 2014 para Câmara de Deputados. 
Figura 1 - População, Candidatos e Eleitos para Câmara de Deputados conforme Gênero: Brasil, 2014

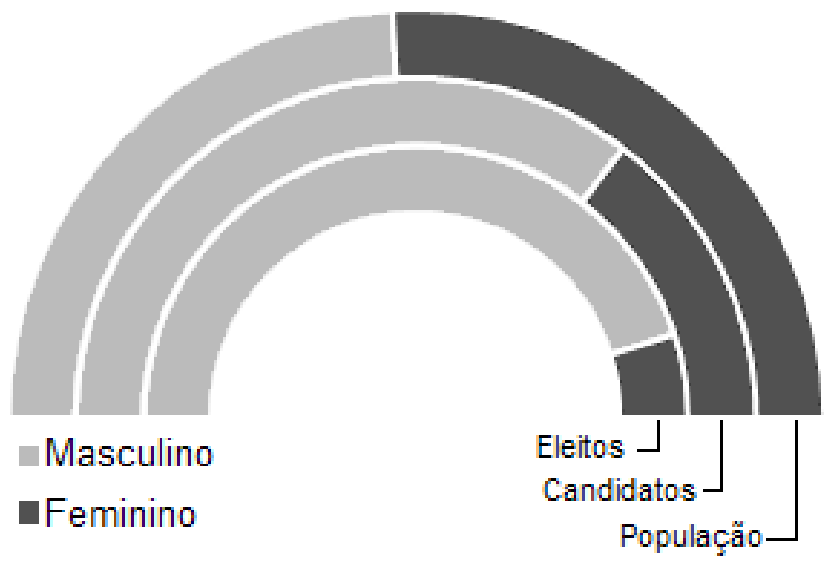

Fonte: Elaboração própria.

Tabela 2 - Representação Descritiva segundo Gênero na Eleição de 2014 para a Câmara de Deputados

\begin{tabular}{|l|c|c|}
\cline { 2 - 3 } \multicolumn{1}{c|}{} & \multicolumn{2}{c|}{ Proporção da Representação Ideal } \\
\cline { 2 - 3 } \multicolumn{1}{c|}{} & Entre Candidaturas & Entre Eleitos \\
\hline Homens & 1,5 & 1,9 \\
\hline Mulheres & 0,6 & 0,2 \\
\hline
\end{tabular}

Fonte: Elaboração própria.

O número de candidatas nas eleições de 2014 para a Câmara dos Deputados aproxima-se do percentual erigido como mínimo pela legislação. Contam-se, entre as candidaturas que efetivamente participaram do pleito, 1.795 mulheres, número que perfaz 29\% do total. Inobstante, a proporção de mulheres eleitas está muito abaixo desta proporção: a bancada feminina corresponde a apenas $10 \%$ da Câmara dos Deputados, com 51 membros. Embora componham a maioria numérica da cidadania brasileira, as mulheres são subrepresentadas tanto no acesso à disputa política quanto na participação política no Parlamento. Entre os eleitos, o gênero masculino recebe 
quase o dobro da representação descritiva devida (190\%), enquanto o gênero feminino recebe apenas um quinto (20\%). É mais difícil para as mulheres acessarem a política partidária e, quando acessam, é ainda mais difícil elegerem-se.

\section{Desigualdade Segundo cor ou raça}

A investigação da questão racial no Brasil perpassa o problema da identificação. Conforme Anjos (2013), a formação das estatísticas oficiais foi influenciada pela intenção de atestar um projeto da elite nacional que associava amadurecimento civilizatório com branqueamento da população. Posteriormente, a adoção da categoria intermediária "parda" favoreceu este processo de branqueamento ao contingenciar a adoção do "branco" por parte dos mestiços, e do "pardo" por parte dos negros. Como resultado, Anjos (2013, p. 111) demonstra que entre 1872 e 1960 a categoria "preta" caiu para metade de sua proporção original nas estatísticas oficiais. Na segunda metade do século XX o esforço da estatística oficial comprometeu-se com a ideologia da democracia racial, o que para Anjos reforça a estratégia do branqueamento ao desestimular a construção e o uso de estatísticas sobre a classificação de raça. Com o aporte de movimentos sociais e de parte da pesquisa acadêmica, uma alternativa para trabalhar os dados existentes é considerar o conjunto de declarantes "pardos" e "pretos" como população negra ou afrodescendente (afro-brasileira).

A Figura 2 apresenta a distribuição da população brasileira, dos candidatos e dos eleitos, conforme manifestação de cor ou raça. De acordo com o discutido, pode-se considerar o conjunto "pardo" e "preto" como um contínuo de afro-brasileiros. Majoritária na população, a participação afro-brasileira chega a $40 \%$ das candidaturas e apenas 20\% dos eleitos para a Câmara dos Deputados em 2014. 
Figura 2 - População, Candidatos e Eleitos para Câmara de Deputados conforme Cor ou Raça: Brasil, 2014

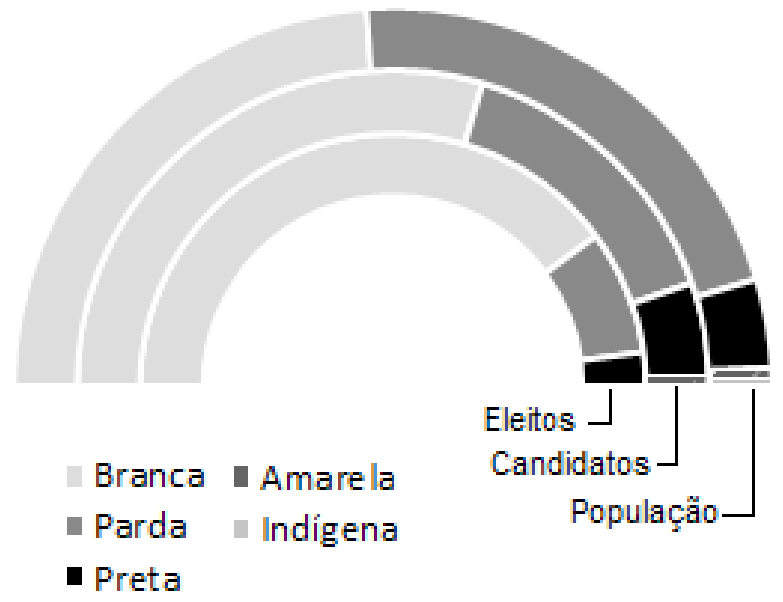

Fonte: Elaboração própria.

Os cidadãos que declaram cor ou raça "branca" ocupam um espaço desproporcional tanto nas candidaturas à Câmara dos Deputados, quanto - e mais expressivamente - entre os eleitos. Os cidadãos afrodescendentes, indígenas e também o grupo que declara cor ou raça "amarela" (origem asiática) estão sub-representados. A Tabela 3 abre os dados para investigação da desigualdade de acesso a cadeiras da Câmara dos Deputados, contendo dados tanto para o conjunto afro-brasileiro quanto para a subdivisão "parda" e "preta".

Tabela 3 - Representação Descritiva segundo Cor ou Raça na Eleição de 2014 para a Câmara de Deputados

\begin{tabular}{|c|c|c|}
\cline { 2 - 3 } \multicolumn{1}{c|}{} & \multicolumn{2}{c|}{ Proporção da Representação Ideal } \\
\cline { 2 - 3 } \multicolumn{1}{c|}{} & Entre Candidaturas & Entre Eleitos \\
\hline Branca & 1,2 & 1,7 \\
\hline Afro-brasileiros & 0,8 & 0,4 \\
\hline Parda & 0,7 & 0,4 \\
\hline Preta & 1,3 & 0,6 \\
\hline
\end{tabular}

continua 
continuação

\begin{tabular}{|c|c|c|}
\hline Amarela & 0,5 & - \\
\hline Indígena & 0,9 & - \\
\hline
\end{tabular}

Fonte: Elaboração própria.

A representação descritiva da população que se declara branca alcança $120 \%$ da devida entre as candidaturas e $170 \%$ na Câmara dos Deputados eleita. Por outro lado, a população afrobrasileira possui $80 \%$ da representação descritiva devida entre as candidaturas e metade desta presença (40\%) entre os eleitos. O fato de que uma proporção relativamente elevada de declarantes da cor ou raça "preta" lançam candidaturas (maior do que "branca" e quase o dobro de "parda") pode ser um indício do componente político da questão racial: a identidade de raça negra revelar-se-ia como um componente valioso da inserção política dos candidatos. Tal inserção, no entanto, esbarra nas eleições. Como apontado, entre os eleitos os afro-brasileiros obtêm menos da metade da representação descritiva ideal e, considerando apenas o conjunto que se declara "preto", a representação descritiva não ultrapassa $60 \%$ do ideal. Assim, mesmo que os cidadãos afro-brasileiros tenham relativo sucesso ao inseriremse na política, propondo candidaturas, o processo eleitoral possui um efeito limitador expressivo de sua presença na Câmara de Deputados.

\section{Desigualdade Segundo grau de instrução (EScolarização)}

Um dos maiores avanços da democracia brasileira recente ocorreu em 1985, com a promulgação da Emenda Constitucional no 25, que estabeleceu o voto facultativo para os não alfabetizados e extinguiu o censo literário na política nacional. Inscrita posteriormente na Constituição Federal de 1988, esta medida restaurou um direito que havia sido suprimido durante o Império, pela Lei Saraiva, em 1881. Ao 
longo do século $\mathrm{XX}$, a proibição do voto aos analfabetos foi fator de enorme exclusão política: atingia potencialmente, em 1950, 20 milhões de brasileiros com idade de 20 anos ou mais, número este maior do que os 11 milhões e meio de eleitores inscritos. A restituição do direito ao voto significa, atualmente, a inclusão de sete milhões e meio de eleitores alistados, ou $5,4 \%$ do total ${ }^{4}$.

Embora para inscrição de candidaturas sejam requeridas as aptidões de ler e escrever, na realidade do acesso à concorrência para a Câmara dos Deputados e, com força ainda maior, para a conquista de uma cadeira, a posse de um diploma de nível superior parece ser um critério influente. Bacharéis, licenciados e outros diplomados em nível superior correspondem a uma minoria de $10 \%$ da população, mas ocupam 50\% das candidaturas à Câmara dos Deputados e $80 \%$ das cadeiras após as eleições - como expressa a Figura 3.

Figura 3 - População, Candidatos e Eleitos para Câmara dos Deputados conforme Grau de Instrução: Brasil, 2014.

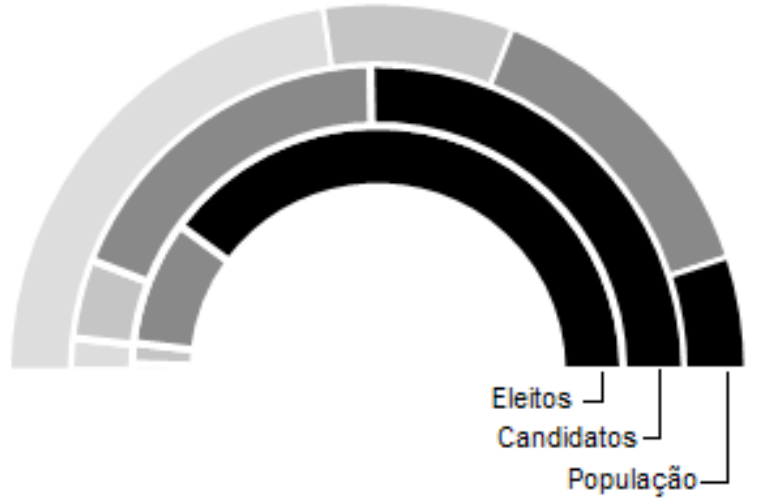

Sem instrução e fundamental incompleto

Fundamental completo e médio incompleto

Médio completo e superior incompleto

- Superior completo

Fonte: Elaboração própria.

Fontes: IBGE (Censo de 1950) e TSE (Eleição de 1950; Estatísticas do Eleitorado). 
Considerando o trabalho parlamentar como espécie específica de atividade intelectual (a argumentação, o debate, a deliberação), não é difícil justificar como característica positivamente distintiva para aqueles que almejam este "posto de trabalho" a posse de um curso de nível superior. O eleitor pode considerar-se melhor representado por um indivíduo que possua atributos diferenciados de educação, o que pode estar associado, em tese, a uma capacidade diferenciada de realizar o trabalho da representação. Não obstante a legitimidade deste argumento, o acesso e a exclusão da universidade parece um critério estruturador da desigualdade de acesso à política nacional. Sob este ponto de vista, o acesso à educação é um critério de exclusão política de uma grande maioria, em favor de uma minoria. A Tabela 4 quantifica esta exclusão.

Tabela 4 - Representação Descritiva segundo Grau de Instrução na Eleição de 2014 para a Câmara dos Deputados

\begin{tabular}{|l|c|c|}
\cline { 2 - 3 } \multicolumn{1}{c|}{} & \multicolumn{2}{c|}{ Proporção da Representação Ideal } \\
\cline { 2 - 3 } & Entre Candidaturas & Entre Eleitos \\
\hline Sem instrução e fundamental incompleto & 0,1 & 0,02 \\
\hline $\begin{array}{l}\text { Fundamental completo e médio } \\
\text { incompleto }\end{array}$ & 0,5 & 0,2 \\
\hline Médio completo e superior incompleto & 1,3 & 0,6 \\
\hline Superior completo & 5,0 & 7,9 \\
\hline
\end{tabular}

Fonte: Elaboração própria.

A educação formal é um critério de distorção da representação descritiva na Câmara dos Deputados: o conjunto dos cidadãos que não possuem o ensino fundamental completo possui $2 \%$ da representação descritiva devida; os que não possuem ensino médio possuem $20 \%$; os que não possuem nível superior, $60 \%$. Já os cidadãos com grau superior possuem quase oito vezes mais representantes (790\%) do que sua presença na sociedade justificaria. $\mathrm{O}$ mesmo padrão de distorção, 
embora com menor amplitude, está presente entre o conjunto de candidatos a uma cadeira da Câmara. Esta informação parece direcionar a razão desta desigualdade para fora do comportamento do eleitor, na medida em que situa a educação formal no que Coradini (2002) considera condições sociais e culturais para o surgimento do interesse em acessar a esfera de atividades políticas.

Em seu estudo sobre a inserção dos brasileiros na política, Coradini (2002) aponta que o grau de escolarização não é apenas um dos recursos sociais que os indivíduos podem converter em recursos políticos. Também se configura como um recurso associado ao surgimento do interesse, da disposição e da prática da atividade política. Realizando o caminho inverso do autor, pode-se salientar que a escolarização é tanto um recurso valioso dentro do campo político (desigualdade nas eleições), como uma causa do engajamento na atividade política (desigualdade nas candidaturas). Esta interpretação lança luzes sobre a dimensão política do controle de acesso à educação e, especialmente, à educação superior.

\section{Desigualdade segundo grupos de ocupação}

Pode-se presumir que a estrutura da desigualdade política relativa à ocupação profissional dos cidadãos está associada à questão educacional. Inobstante, o pertencimento à determinada categoria profissional - e um diploma de certo tipo - altera as oportunidades de acesso dos indivíduos à vida política nacional, como atesta Coradini (2006). Ademais, o autor sustenta que na política brasileira recente a existência de militância "corporativa" - nas associações, ordens, conselhos de trabalhadores, empresários ou profissionais liberais - possui uma influência decisiva sobre a entrada na política. Na composição da Câmara dos Deputados, entre 1978 e 2003 cresceu de maneira generalizada a participação de deputados que em suas 
carreiras prévias possuíram atuação em sindicatos de trabalhadores ou de empresários, bem como em associações de médicos, advogados, engenheiros e assemelhados (CORADINI, 2006, p. 155). A estrutura ocupacional na qual se insere o indivíduo, portanto, importa para as condições objetivas de ele desenvolver uma atividade política e, eventualmente, chegar à política nacional.

Para simplificar a análise foram criados quatro conjuntos de ocupações. O grupo de "trabalhadores" (a) reuniu a população economicamente ativa nos grupos ocupação da atividade principal técnicos de nível médio e trabalhadores de apoio administrativo, dos serviços pessoais, da agropecuária, operários qualificados, operadores de máquinas e elementares. No grupo de "trabalhadores" foram incluídos também os profissionais da educação. Os outros três grupos reúnem (b) profissionais de nível superior (ocupações como advogados, médicos, engenheiros); (c) diretores e gerentes de empresas privadas; e (d) membros das Forças Armadas e das políticas ${ }^{5}$. A Figura 4 apresenta a distribuição social, no conjunto das candidaturas e entre os deputados eleitos.

Para caracterização dos eleitos foram utilizados os dados do TSE. Os deputados eleitos que informaram ocupação "Deputado", outro cargo político ou "outros", foram reclassificados conforme informação da Câmara dos Deputados. Deputados que declararam "Administrador" foram enquadrados como diretores do setor privado. Para deputados com mais de uma informação, considerou-se a primeira ou a que denotasse ocupação e não área de formação. 
Figura 4 - População, Candidatos e Eleitos para Câmara de Deputados conforme Ocupação: Brasil, 2014

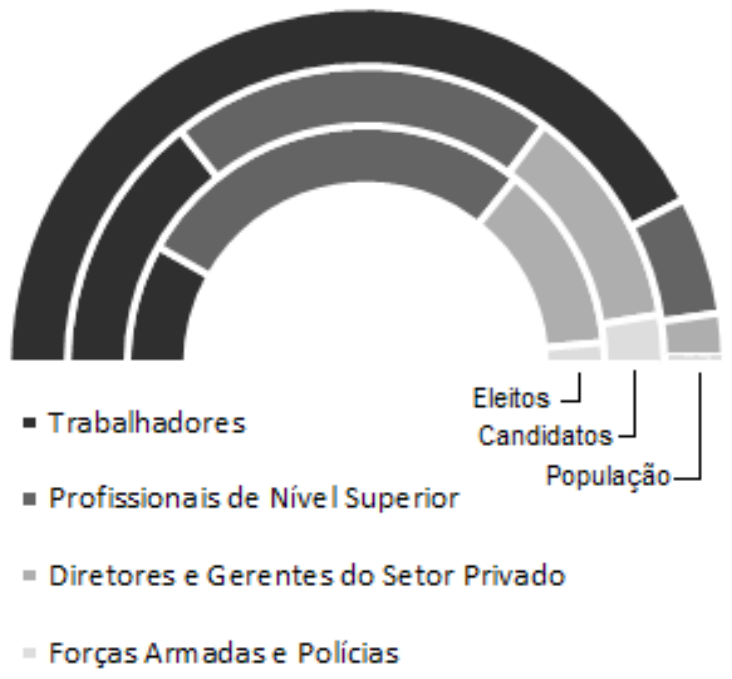

Fonte: Elaboração própria.

Embora ocupem $85 \%$ da população economicamente ativa, os "trabalhadores" são menos de $30 \%$ dos candidatos à Câmara dos Deputados e apenas $16 \%$ dos eleitos. A Tabela 5 analisa com maior acuidade este critério de desigualdade.

Tabela 5 - Representação Descritiva segundo Ocupação na Eleição de 2014 para a Câmara de Deputados

\begin{tabular}{|l|c|c|}
\cline { 2 - 3 } \multicolumn{1}{c|}{} & \multicolumn{2}{c|}{ Proporção da Representação Ideal } \\
\cline { 2 - 3 } \multicolumn{1}{c|}{} & Entre Candidaturas & Entre Eleitos \\
\hline Diretores e Gerentes do Setor Privado & 6,2 & 6,5 \\
\hline Profissionais de Nível Superior & 3,9 & 5,2 \\
\hline Forças Armadas e Polícias & 8,6 & 4,7 \\
\hline Trabalhadores & 0,3 & 0,2 \\
\hline
\end{tabular}

Fonte: Elaboração própria. 
Diretores e gerentes do setor privado possuem seis vezes e meia a representação descritiva ideal, índice próximo de sua presença no conjunto dos candidatos. Os profissionais de nível superior possuem mais de cinco vezes sua representação descritiva ideal, o que supera significativamente sua presença entre as candidaturas. Os membros das Forças Armadas e polícias, embora participem das candidaturas em uma proporção quase nove vezes superior a sua presença social, possuem no Parlamento pouco menos de cinco vezes sua representação ideal. Os "trabalhadores", por fim, possuem menos de um terço da participação ideal nas candidaturas (30\%) e um quinto da representação ideal na Câmara dos Deputados (20\%). Revela-se, deste modo, uma situação de profunda desigualdade da representação descritiva associada à ocupação profissional, em prejuízo dos trabalhadores.

\section{Desigualdade segundo Riqueza}

Os estudos sobre a concentração de riqueza ou patrimônio ganharam atenção atualmente, em especial em relação ao problema da desigualdade. Considerando que estão disponíveis dados de patrimônio dos candidatos e deputados eleitos, na base do TSE, é possível investigar a desigualdade da distribuição de patrimônio na sociedade, no conjunto das candidaturas e entre os deputados federais eleitos. Em relação à população brasileira, podem ser aproveitados dados tributários divulgados pela Receita Federal do Brasil ${ }^{6}$. A Figura

\footnotetext{
Os dados apresentam a quantidade de declarações de Imposto de Renda em faixas do patrimônio declarado. Considerando que a declaração é obrigatória para pessoas com patrimônio maior do que 300 mil reais, pode-se presumir que os nãos declarantes possuem um patrimônio menor. Assim, os brasileiros maiores de 18 anos (conforme PNAD 2012) foram agregados nesta faixa, permitindo uma visão do total da população brasileira - e não apenas dos contribuintes. Esta medida é bastante conservadora, considerando inclusive que quase $40 \%$ dos declarantes do Imposto de Renda informam patrimônio de até mil reais. Os dados são de 2012. (BRASIL, 2015).
} 
5 mostra como a distribuição da riqueza é muito diferente entre a população brasileira, os candidatos e os eleitos na disputa para Câmara de Deputados de 2014.

Figura 5 - Representação Descritiva segundo Grupos de Riqueza na Eleição de 2014 para a Câmara de Deputados

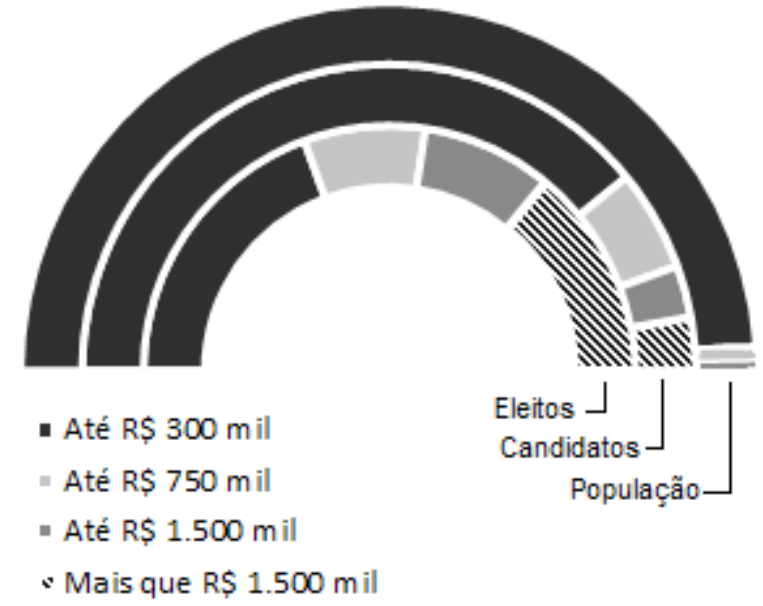

Fonte: Elaboração própria.

A quase totalidade da população brasileira encontra-se na faixa patrimonial de até 300 mil reais. Entre os candidatos, as faixas de maior riqueza, somadas, ocupam pouco mais de 20\% dos casos. Já entre os eleitos, as faixas de maior riqueza são majoritárias em conjunto, alcançando mais de 60\% da Câmara dos Deputados - com destaque para os mais ricos (patrimônio de mais de um milhão e meio de reais), quase 30\% dos deputados eleitos. Esta distorção deve chamar menos a atenção quando se repara na remuneração dos cargos políticos. Apenas com seu salário líquido mensal, um Deputado Federal seria capaz de acumular mais de um milhão de reais no curso de um mandato. Só o fato de que 56\% da Câmara dos Deputados de 2014 foi reeleita já justificaria, sem considerar o exercício de outras funções públicas, 
uma diferença substancial no patrimônio dos deputados quando comparado com o da população em geral.

Em que pese esta consideração, fato é que no quesito riqueza tanto o conjunto de candidatos quanto o de deputados eleitos diferemse em grande media, em termos descritivos, da população brasileira. A Tabela 6 explora esta situação.

Tabela 6 - Representação Descritiva segundo Riqueza na Eleição de 2014 para a Câmara de Deputados

\begin{tabular}{|l|c|c|}
\cline { 2 - 3 } \multicolumn{1}{c|}{} & \multicolumn{2}{c|}{ Proporção da Representação Ideal } \\
\cline { 2 - 3 } \multicolumn{1}{c|}{} & Entre Candidaturas & Entre Eleitos \\
\hline Até $R \$ 300 \mathrm{mil}$ & 0,8 & 0,4 \\
\hline Até $\mathrm{R} \$ 750 \mathrm{mil}$ & 7,5 & 11,2 \\
\hline Até $\mathrm{R} \$ 1.500 \mathrm{mil}$ & 11,9 & 37,4 \\
\hline Mais que $\mathrm{R} \$ 1.500 \mathrm{mil}$ & 20,0 & 99,2 \\
\hline
\end{tabular}

Fonte: Elaboração própria.

Enquanto a parte mais pobre da população (patrimônio de até 300 mil reais) possui menos da metade da representação política devida (40\%), os mais ricos (patrimônio de mais de 1.500 mil reais) possuem nada menos do que 99 vezes sua representação descritiva ideal (992\%). Em relação às candidaturas, o processo eleitoral tanto diminui a presença dos indivíduos com menor patrimônio como, para todas as faixas seguintes, aumenta a distorção da representação.

\section{Conclusão}

Se o Brasil fosse uma representação em grande escala de seu Parlamento, seria um país de homens brancos. Eles possuiriam educação superior, seriam empresários ou profissionais especializados e seriam ricos. Este não é o Brasil. Sob o ponto de vista da representação 
descritiva, dizer que o Parlamento é reflexo da sociedade brasileira simplesmente não é verdade.

O sucesso da governabilidade democrática, que permitiu contornar os problemas econômicos crônicos e promover uma resposta à exclusão e à desigualdade social levou a Ciência Política a tratar com certo otimismo a Nova República. As jornadas de junho de 2013 e o descrédito persistente e agravado dos cidadãos nas instituições políticas exigem que a questão da representação política seja investigada, discutida, problematizada. A visão da representação descritiva apresenta um ângulo da democracia brasileira que exibe a desigualdade de acesso e presença na política nacional.

A política nacional possui dois filtros muito estreitos: a seleção de candidaturas pelos partidos e o processo eleitoral. Por estes filtros passam cidadãos de certo tipo, possuidores de certos predicados. As origens destes limites podem ser procuradas nas instituições formais da representação eleitoral, na estrutura de acesso ao espaço público ou em uma cultura marcada pelo preconceito de gênero, de raça e de classe. Embora futuras investigações sejam necessárias para melhor apreender as causas da desigualdade na representação descritiva, é seguro afirmar que este é um fenômeno multicausal.

Esta pesquisa investigou cinco critérios que estruturam a desigualdade política no país. É importante dividir estes critérios entre aqueles que expressam um componente pessoal dos cidadãos - gênero e cor ou raça - e aqueles que se aproximam da noção de classe - instrução formal, ocupação, riqueza. Contudo, é inegável o encadeamento das características pessoais com a estruturação da desigualdade incorporada nas classes sociais. Este encadeamento, que possui uma contingencialidade social e historicamente determinada, chega à política potencializando a exclusão de mulheres e afro-brasileiros. O caso da representação das mulheres vis-à-vis sua ocupação no trabalho é sintomático desta situação, em especial 
considerando os esforços legais recentes para fomentar a participação das mulheres na política.

As mulheres trabalhadoras possuem na Câmara dos Deputados $2 \%$ da representação descritiva devida (contra 30\% dos homens), as mulheres profissionais de nível superior 110\% (contra $1.110 \%$ dos homens) e as dirigentes de empresas privadas $160 \%$ (contra 950\% dos homens). Embora a representação descritiva dos homens seja maior em todos os grupos de ocupações, a desigualdade é maior entre trabalhadores e trabalhadoras ( 15 vezes) do que entre os e as profissionais de nível superior (10 vezes) e entre os e as dirigentes de empresas privadas (seis vezes). Em que pesem as disposições legais voltadas para assegurar a participação feminina nas eleições, esta participação ainda é muito baixa, sobretudo entre as mulheres trabalhadoras em ocupações médias, intermediárias, elementares e na educação.

O caso das cotas de candidatura para mulheres mostra como é necessário mais do que arranjos formais para garantir sua presença política: existem desafios provenientes das desigualdades da sociedade brasileira. Neste sentido, políticas como a de cotas no acesso às Universidades associadas à população declarada preta, parda e indígena (BRASIL, 2012) podem ter efeito sobre a representação da população afro-brasileira na medida em que favorecem sua inserção nas redes que participam da política. O cruzamento entre a declaração de cor e raça e o nível de instrução formal permite investigar esta relação. Os afro-brasileiros sem nível superior possuem na Câmara de Deputados uma representação descritiva de $13 \%$ do correspondente a sua presença social, enquanto a representação descritiva dos brancos sem nível superior alcança 34\%. Entre a população com nível superior, a representação descritiva afro-brasileira alcança $580 \%$ de sua presença social, enquanto a dos brancos chega a $890 \%$. Portanto, a diferença da 
representatividade mensurada pela declaração de cor ou raça entre os não graduados é de $265 \%$, entre os graduados ela cai para $150 \%$.

A representação na democracia liberal presume a diferença dos eleitos em relação ao corpo de eleitores. A escolha do eleitor recai sobre características que distinguem positivamente os candidatos liderança, capacidade de oratória, atributos de erudição, posição e articulação social. Também são influenciadas pela propaganda, ou seja, pela capacidade de o candidato investir recursos financeiros em sua campanha. Nenhum destes atributos é homogeneamente distribuído na sociedade, de maneira que a estrutura das desigualdades sociais é transmitida para a política representativa. Assim as origens da desigualdade na política nacional brasileira não recaem apenas sobre as condições de disputar os votos e vencer uma eleição. Elas estão presentes na estrutura sociopolítica do país.

Como mostra a variação do indicador de representação descritiva entre as candidaturas e os eleitos, as mulheres, os afrobrasileiros, os menos escolarizados, os trabalhadores e os pobres não só estão sub-representados entre os eleitos para a Câmara dos Deputados, como também participam de maneira desproporcionalmente inferior no total de candidaturas. Com exceção dos conjuntos declarantes de cor ou raça preta, do grupo com instrução média e superior incompleta e dos membros de Forças Armadas e policiais, as eleições possuíram o efeito de aumentar a representação de grupos que já estavam com participação desproporcionalmente elevada nas candidaturas e reduzir a representação daqueles que participam das eleições em proporção menor do que a indicada por sua presença na sociedade.

Tanto no caso das mulheres quanto da população afrobrasileira, pode-se inferir que melhores condições de igualdade no mercado de trabalho e no acesso à educação superior, respectivamente, possuem o potencial de diminuir a desigualdade na representação descritiva. É evidente, contudo, que estas são mudanças de longo 
prazo. Enquanto isso, deve-se reconhecer que não é bom para a democracia brasileira conviver com tal nível de desigualdade dos conjuntos sociais na representação do Parlamento. Dentre as medidas concretas que poderiam favorecer a participação das mulheres e dos afro-brasileiros na política encontra-se a estipulação de reserva de vagas nas eleições parlamentares, além de maiores incentivos para que os partidos valorizem a participação política dos mesmos.

Políticas públicas que diminuam a importância da estrutura de desigualdade social na política nacional podem estar se tornando ainda maisurgentes.Sobo ponto devista da representação democráticaliberal, os programas de governo e as promessas eleitorais dos candidatos são percebidos como liames entre a vontade dos eleitores (seus interesses e também suas opiniões) e a política pública governamental. Ainda que os candidatos e os eleitos não surjam como membros das minorias sociais e econômicas, seria esperado encontrar entre as bandeiras e plataformas presentes nas eleições aquelas direcionadas à defesa dos interesses minoritários. No entanto, a literatura tem destacado que a representação via partidos, programas e promessas pode estar em mutação, seja no ocidente (MANIN, 2012) ou mesmo no Brasil - pais no qual nunca chegou a desempenhar um papel estruturador das eleições parlamentares (PAIVA; BRAGA; PIMENTEL, 2007).

Pode-se inquirir, portanto, em que medida o enfraquecimento dos partidos políticos e a ausência de uma política de ideias não abre mais espaço para que a atuação dos parlamentares recorra aos aspectos mais pessoais, particulares e individuais de cada representante. No contexto de negação dos partidos e das organizações políticas, uma representação descritiva extremamente desigual como a brasileira pode favorecer uma política pública igualmente reforçadora das desigualdades. Esta proposição, cuja verificação depende de outros esforços investigativos, aponta para um limite da integração política daquela que se soma como a maioria dos brasileiros em termos 
demográficos. Certo é que a persistência da atual estrutura de desigualdade da representação descritiva nacional, agravada ou não pelas transformações da política contemporânea, representa um desafio a ser enfrentado tanto sob o aspecto da consolidação quanto da qualidade da democracia brasileira.

\section{REFERÊNCIAS}

ANJOS, Gabriele. A questão "cor" ou "raça" nos censos nacionais. Indicadores Econômicos FEE, Porto Alegre, v. 41, n. 1, p. 103-118, jan. 2013.

ARATO, Andrew. Representação, soberania popular e accountability. Lua Nova, São Paulo, n. 55-56, p. 85-103, jan. 2002.

ARAÚJO, Clara. Partidos políticos e gênero: mediações nas rotas de ingresso das mulheres na representação política. Revista de Sociologia e Política, Curitiba, n. 24, p. 193-215, jun. 2005.

ARISTÓTELES. Política. Brasília: UNB, 1997.

BARRETO, Alvaro A. de B. Representações das associações profissionais no Brasil: o debate dos anos 1930. Revista de Sociologia e Política, Curitiba, n. 22, p. 119-133, jun. 2004.

BRASIL. Lei $\mathbf{n}^{\mathbf{0}} \mathbf{1 2 . 7 1 1}$, de 29 de agosto de 2012. Dispõe sobre o ingresso nas universidades federais e nas instituições federais de ensino técnico de nível médio e dá outras providências. Disponível em: <http://www.planalto.gov.br/ccivil_03/_ ato2011-2014/2012/lei/112711.htm>. Acesso em: 3 nov. 2015.

BRASIL. Secretaria da Receita Federal. Tabelas rendas e bens. Disponível em: $<$ http://idg.receita.fazenda.gov.br/dados/receitadata/estudos-e-tributarios-eaduaneiros/trabalhos-academicos/tabelas-renda-e-bens.xlsx>. Acesso em: 5 nov. 2015.

CORADINI, Odaci L. Escolarização, militantismo e mecanismos de "participação" política. In: HEREDIA, Beatriz; TEIXEIRA, Carla; BARREIRA, Irlys. (Org.). Como se fazem eleições no Brasil: estudos antropológicos. Rio de Janeiro: Relume Dumará, 2002.

CORADINI, Odaci L. Representação profissional e elites políticas no Brasil no período recente. Política \& Sociedade, Florianópolis, n. 9, p. 123-161, out. 2006.

DAHL, Robert A. Sobre a democracia. Brasília: UNB, 2001. 
KELSEN, Hans. A democracia. São Paulo: Martins Fontes, 2000.

MANIN, Bernard. Principes du gouvernement représentatif. Paris: Flammarion, 2012.

MILL, John Stuart. Considerações sobre o governo representativo. São Paulo: IBRASA, 1964.

MOSCA, Gaetano. The ruling class. Nova York: McGraw-Hill Book Company, 1939.

PAIVA, Denise; BRAGA, Maria do Socorro S.; PIMENTEL JUNIOR, Jairo Tadeu Pires. Eleitorado e partidos políticos no Brasil. Opinião Publica, Campinas, v. 13, n. 2, p. 388-408, 2007.

PHILLIPS, Anne. De uma política de idéias a uma política de presença? Estudos Feministas, Florianópolis, v. 9, n. 2, p. 268-290, jul. 2001.

PITKIN, Hanna F. The concept of representation. Berkeley: University of Califórnia, 1967.

SANTOS, Wanderley G. dos. Poliarquia em 3D. Dados, Rio de Janeiro, v. 41, n. 2, p.207-281, 1998.

YOUNG, Iris M. Polity and group difference: a critique of the ideal of universal citzenship. Ethics, Chicago, v. 99, n. 2, p. 250-274, jan. 1989. 